\title{
Performance and Life-Time Stability of Perovskite Solar Cells
}

\author{
O. Ourahmoun \\ Faculty of Electrical and Computer Engineering, Mouloud Mammeri University (UMMTO), \\ Tizi-Ouzou, Algeri, Algeria
}

\begin{abstract}
Perovskite-based solar cells have attracted a great deal of attention due to their rapid increase in power conversion, which has reached to 24.2\%. The performance of perovskite solar cells depends on several parameters such as the absorber layer, the electron transport layer, the hole transport layer, and the electrodes, and the deposition technics. Moisture, oxygen, tem-perature and light intensity are environmental factors which can influence the stability of the photovoltaic devices and dete-riorate the performance. Also, the toxicity, caused by the presence of lead $(\mathrm{Pb})$ content, is an obstacle for the commerciali-zation of the perovskite solar cells. The use of free-lead absorber layer is discussed, and solution to improve performances and stability of perovskite solar cells are proposed.
\end{abstract}

Keywords: Perovskite Solar Cells, Moisture, Chemical Decomposition, UV-Light, Temperature, Life-Time, Improvement.

\section{INTRODUCTION}

Perovskite-based solar cells (PSCs) with the composition $\mathrm{ABX} 3$ active layer $\left[\mathrm{A}=\mathrm{CH}_{3 N H}{ }^{+}(\mathrm{MA}), \mathrm{NH}=\mathrm{CHNH}^{+}(\mathrm{FA})\right.$ or $\mathrm{Cs}^{+} ; \mathrm{B}=\mathrm{Sn}$ or $\mathrm{Pb} ; \mathrm{X}=\mathrm{Cl}, \mathrm{Br}$ or I] have attracted a great deal of attention due to their rapid increase in power conversion (PCE), which has reached to $24.2 \%$ [1]. PSCs are promising candidates for achieving high efficiencies due to their band gap around 1.55 $\mathrm{eV}$, their high absorption coefficient, long charge carrier diffusion path, low recombination. The PSCs are made using different technics such as roll to roll, printing [2], spin-coating [3], and spray methods. The deposition of the layers at low temperature, and solution processing make it easy, low cost technology and possibility to realize large area cells using flexible substrates. In PSCs, organic and inorganic materials are used as hole transport layer [4].

The environmental factors can influence the stability of the PSC devices. Such as moisture, oxygen, temperature, and light intensity. The disadvantage of this cells is the sensitivity to humidity and oxygen. In the presence of water, the yield of this cells decreases. The toxicity of the lead used in the absorber layer is another disadvantage of this device.
Two typical architectures are constructed: mesoscopic structure and planar structure. In addition, the structure can be subdivided into n-i-p structure or p-i-n structure, depending on the deposition order. In general, the mesoscopic n-i-p structure is widely used to fabricate high-performance devices. This structure is composed of the fluorine doped tin oxide (FTO) electrodes, hole blocking layer (HBL), electron transport layer (ETL), hole transporting layer (HTL), perovskite absorber layer as photoactive layer.

Generally, high performance PSCs do not retain their efficiencies and degrade in a span of time ranging from few minutes to couple of days, whereas the cells which demonstrate better stability lacks high performance. To improve the stability of PSCs, systematic understanding of the degradation mechanisms and their effect on the device performance is essential.

This work presents the progress of perovskite solar cells. The performance of the cells depends on the structure, architecture of the device, the hole transport materials, electron transport materials, and the absorber layers. The use of free-lead absorber layer is discussed. Another point presented related to the stability of the materials used in PSCs and their effect on the device stability. Solution to improve performances and stability of perovskite solar cells are proposed.

\section{STRUCTURE OF THE PEROVSKITE SOLAR CELLS}

The schematic structures of perovskite solar cells are shown in Fig.1. The structure of PSCs can be divided into three categories: perovskite sensitized mesoporous or $n-i-p$ structure, planar heterojunction structure and inverted or p-i-n structure. In all structures, after absorbing the incident photons by the perovskite materials, excitons with a low binding energy are generated and dissociated into the free charge carriers.

In planar structure, a perovskite absorber layer is sandwiched between the electron transport layer (ETL) and the hole transport layer (HTL). Two heterojunctions are provided which are the junction between the active layer and HTL, and the junction between absorber and ETL. Different types of materials are used as HTLs, and a compact layer such as $\mathrm{TiO}_{2}$ layer is usually used as an ETL.

In the inverted devices, photogenerated electrons are collected in cathode and photogenerated holes are collected in anode. Organic materials such as PEDOT:PSS and fullerene derivatives are used as HTLs and ETLs, respectively.

The advantages of this structure are: $\mathrm{TiO}_{2}$ compact layer is replaced by organic ETMs which avoids the high temperature annealing process and device structure is simpler. The stability of the structure can be improving by removing $\mathrm{TiO}_{2}$ layer which cause stability under UV light. The materials and process methods for this structure provide the fabrication of flexible perovskite solar cells. the high cost spiro-OMeTAD can be replaced by other organic materials. ITO or FTO are widely used as anodes. $\mathrm{Au}, \mathrm{Cu}$ and $\mathrm{Ag}$ are used as cathodes. Recently carbon based contact such as graphene are used as cathodes. And graphene oxide is used as HTL. 


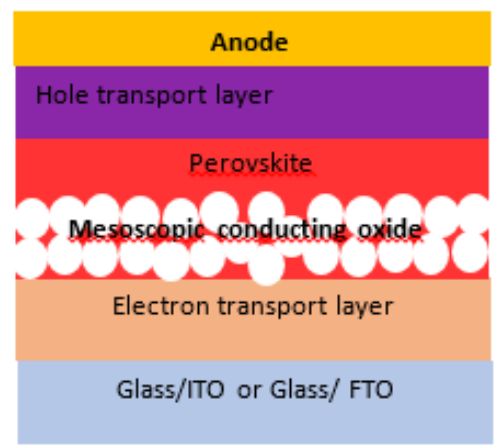

(a)

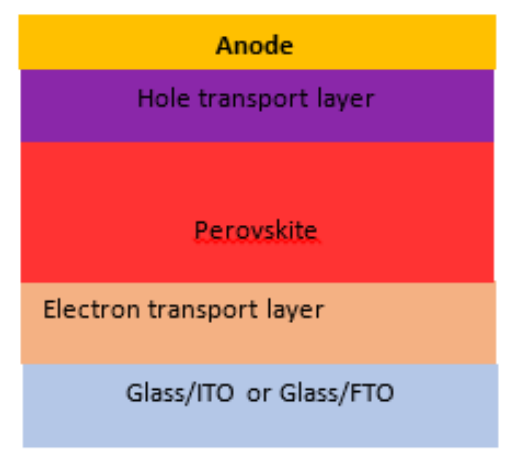

(b)

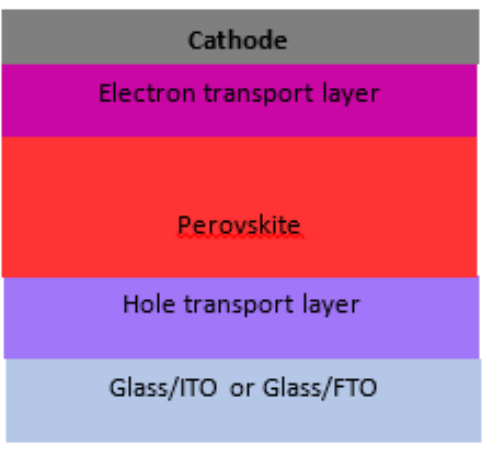

(c)

Figure 1. Different structure of perovskite solar cell: (a) mesoscopic, (b) planar, (c) inverted planar

\section{FABRICATION METHODS}

To fabricate large area perovskite films of high quality: good film uniformity, reduced surface roughness, and low density of structural defects, such as pinholes, various thin-film deposition technologies have been developed, including spin-coating, optimized for large areas, doctor blading, slot-die contact, printing, spray deposition, soft-cover deposition, dip coating, and vapor based deposition. For industrial application, the second step is to fabricate solar modules, and the third step is to integrate multiple solar modules into solar panels. for large area devices and modules, transparent conductive electrodes (TCO) must be considered in terms of both sheet resistance and cost. Due to the sheet resistance of the TCO, the fill factor decreases significantly when the active area of a single solar cell device exceeds a certain threshold. FTO is the most expensive material in perovskite cells. It is necessary to develop low cost electrodes based on conducting organic materials, and fabricate flexible perovskite solar cells.

In PSCs the metallic electrodes such as $\mathrm{Au}, \mathrm{Ag}$, and $\mathrm{Cu}$ are deposited using thermal evaporation under vacuum $\left(10^{-6} \mathrm{mbar}\right)$.

\section{PERFORMANCE OF THE PEROVSKITE SOLAR CELLS}

A photovoltaic performance of a solar cell is determined by the open circuit voltage (Voc), short circuit current (Jsc), fill factor (FF), and power conversion efficiency (PCE). The high crystalline structure of the perovskite material led to high carrier mobility and high conductivity of the charge carriers. Then good charge transport properties. The origin of high $\mathrm{V}_{\text {OC }}$ in PSCs is due the enhancement of the internal charge density level. The perfor- mance of PSCS depends on several parameters such as the architecture of the cell, the material used as active layer, the buffer layers for HTL and ETL and their preparation (solvents and doping) and the type of substrates flexible or rigid, electrodes, and the deposition technics. Table 1, shows the performance of some of cells of the new generation based on perovskite materials. The addition of ITIC plays an important role in improving the quality of the perovskite film such as improving absorption and reducing roughness of perovskite films, and improves thermal stability of the PSCs [7]. The preparation of $\mathrm{TiO}_{2}$ using tetrabutyl-titanate (TT) as precursor is more suitable than $\mathrm{TiO}_{2}$ prepared using titanium diisopropoxide bis (acetylacetonate) (TDB). PSCs with $\mathrm{TT}_{-} \mathrm{TiO}_{2}$ used as ETL show a better PCE (17.4\%) than PSCS with TDB-TiO 2 . Because TT-TiO2 has a superior interface quality, this is due to the reduced recombination carriers leading to an increase of photovoltaic performance [8]. The presence of guanidium molecule (Gua) at the interface between the perovskite absorber MAPbI3 film and the spiro-OMeTAD hole transport layer improves the photovoltaic properties, in particular VoC and the stability of the device. A PCE $=18.54 \%$ and $V_{\text {OC }}$ of $1.1 \mathrm{~V}$ are obtained. Gua eliminate the loss of non-radiative charge carriers in PSCs [9]. The addition of copper bromides to the absorber layers improve cell performance [12]. The use of graphene oxide (GO) and reduced graphene oxide (rGO) as hole transport material are reported. Doping the HTL improve the yield of the PSCs [10]. A new architecture of electrodes is developed. This architecture consists of inserting a protective layer of doped graphene between the anode and the hole transport layer. A protective layer based on $\mathrm{AuCl}_{3}-\mathrm{Gr}$ is used between ITO and PEDOT:PSS to improve hole transport [11]. Other multilayer electrode architecture TCO/metal/TCO can be realized to improve the efficiency of perovskite cells. the use of silver nanowires as electrode is also showed a good performance in the case of organic solar cells.

TABLE 1. PHOTOVOLTAIC PERFORMANCE OF SOME PEROVSKITE SOLAR CELLS

\begin{tabular}{|c|c|c|c|c|c|}
\hline Solar Cell Structure & $\begin{array}{l}\mathrm{J}_{\mathrm{SC}} \\
\left(\mathrm{mA} / \mathrm{cm}^{2}\right)\end{array}$ & $\begin{array}{l}\text { Voc } \\
\text { (V) }\end{array}$ & $\begin{array}{l}\text { FF } \\
(\%)\end{array}$ & $\begin{array}{l}\text { PCE } \\
(\%)\end{array}$ & Ref. \\
\hline FTO/TiO $2 / \mathrm{CH}_{3} \mathrm{NH}_{3} \mathrm{PbI}_{3}-\mathrm{xCl} \mathrm{x}_{\mathrm{x}} / \mathrm{spiro}-\mathrm{OMeTAD} / \mathrm{Au}$ & 15.3 & 0.8 & 55 & 6.7 & [5] \\
\hline $\mathrm{FTO} / \mathrm{SnO}_{2} / \mathrm{TiO}_{2} / \mathrm{MAPbI}_{3}-\mathrm{x} \mathrm{Clx} / \mathrm{Au}$ & 23.68 & 1.06 & 68 & 17.07 & {$[6]$} \\
\hline FTO/TiO $/ \mathrm{CH}_{3} \mathrm{NH}_{3} \mathrm{PbI}_{3} / \mathrm{Po}$-Spiro-OmeTAD/Au & 22.3 & 0.98 & 68.2 & 15.4 & [7] \\
\hline FTO/TiO $2 / \mathrm{CH}_{3} \mathrm{NH}_{3} \mathrm{PbI}$ :ITIC/Po-Spiro-OmeTAD/Au & 23.74 & 1 & 72.8 & 17.59 & [7] \\
\hline FTO/TBD-TiO2/MAPbI3/Spiro-OMeTAD/Au & 20.5 & 1.05 & 63.1 & 13.9 & [8] \\
\hline FTO/TT-TiO $2 / \mathrm{MAPbI}_{3} /$ Spiro-OMeTAD/Au & 23.2 & 1.1 & 68 & 17.4 & [8] \\
\hline ITO/SnO $2 / \mathrm{MAPbI}_{3} /$ spiro-OMeTAD/Au & 22.01 & 1.05 & 69 & 15.98 & [9] \\
\hline
\end{tabular}




\begin{tabular}{|c|c|c|c|c|c|}
\hline ITO/SnO2/MAPbI-(Gua1-xMAx)PbI/spiro-OMeTAD & 22.46 & 1.1 & 75 & 18.54 & [9] \\
\hline $\mathrm{FTO} / \mathrm{TiO}_{2} / \mathrm{CH}_{3} \mathrm{NH}_{3} \mathrm{PbI} / \mathrm{rGO} / \mathrm{FTO}$ (rGO pur) & 15.86 & 0.71 & 45 & 5.10 & [10] \\
\hline $\mathrm{FTO} / \mathrm{TiO}_{2} / \mathrm{CH}_{3} \mathrm{NH}_{3} \mathrm{PbI}_{3} / \mathrm{B}-\mathrm{rGO} / \mathrm{FTO}$ (10\% de bore) & 15.91 & 0.71 & 56 & 7.09 & [10] \\
\hline FTO/TiO $/ \mathrm{CH}_{3} \mathrm{NH}_{3} \mathrm{PbI}_{3} / \mathrm{B}$-rGO/FTO (20\% de Bore) & 16.74 & 0.88 & 60 & 8.96 & [10] \\
\hline ITO/PEDOT:PSS/ $\mathrm{CH}_{3} \mathrm{NH}_{3} \mathrm{PbI}_{3}\left(\mathrm{MAPbI}_{3}\right) / \mathrm{PCBM} / \mathrm{BCP} / \mathrm{Al}$. & 18.94 & 1.01 & 74.0 & 14.6 & [11] \\
\hline $\begin{array}{l}\text { ITO/AuCl } 3-\mathrm{GR} / \mathrm{PEDOT}: \mathrm{PSS} / \mathrm{CH}_{3} \mathrm{NH}_{3} \mathrm{PbI}_{3}\left(\mathrm{MAPbI}_{3}\right) / \\
\text { PCBM/BCP/Al. }\end{array}$ & 20.13 & 1.01 & 77.5 & 15.77 & [11] \\
\hline
\end{tabular}

\section{STABILITY OF THE PEROVKITE SOLAR CELLS}

Perovskite materials are sensitive to air; temperature, moisture, and UV light. The Au electrode can cause degradation when $\mathrm{Au}$ atoms diffuse into the spiro-OMeTAD and perovskite layers under high temperature, which deteriorates performance. Also, low cost Ag electrode react with perovskite materials degrading its performance. Exposure to high temperature is given by the equation (1):

$$
\begin{gathered}
\mathrm{CH}_{3} \mathrm{NH}_{3} \mathrm{PbI}_{3} \stackrel{\mathrm{T}}{\rightarrow} \mathrm{PbI}_{2}+\mathrm{CH}_{3} \mathrm{NH}_{2} \uparrow+\mathrm{HI} \uparrow \text { or } \\
\mathrm{MAPbI}_{3} \stackrel{\mathrm{T}}{\rightarrow} \mathrm{PbI}_{2} \downarrow+\mathrm{MA} \uparrow+\mathrm{HI} \uparrow
\end{gathered}
$$

In the presence of water, MAPbI3 tends to hydrolyze, due to the inherent hygroscopic of the MA cation. The degradation occurs according to the following reaction mechanism:

$$
\begin{aligned}
& \mathrm{CH}_{3} \mathrm{NH}_{3} \mathrm{PbI}_{3} \stackrel{\mathrm{H}_{2} \mathrm{O}}{\longleftrightarrow} \mathrm{PbI}_{2}(\mathrm{~s})+\mathrm{CH}_{3} \mathrm{NH}_{3} \mathrm{I}(\mathrm{aq}) \\
& \mathrm{CH}_{3} \mathrm{NH}_{3} \mathrm{I}(\mathrm{aq}) \stackrel{\mathrm{H}_{2} \mathrm{O}}{\longleftrightarrow} \mathrm{CH}_{3} \mathrm{NH}_{2}(a q)+\mathrm{HI}(a q), \\
& 4 \mathrm{HI}(a q)+\mathrm{O}_{2}(g) \leftrightarrow 2 \mathrm{I}_{2}(\mathrm{~s})+2 \mathrm{H}_{2} \mathrm{O}, \\
& 2 \mathrm{HI}(a q) \leftrightarrow \mathrm{H}_{2}(g)+\mathrm{I}_{2}(\mathrm{~s}) .
\end{aligned}
$$

The decomposition of the perovskite under high temperature and under moisture effect is shown in figure 2 .

PCBM is the most common ETL used in p-i-n planar PSCs due to its excellent conductivity and electron extraction

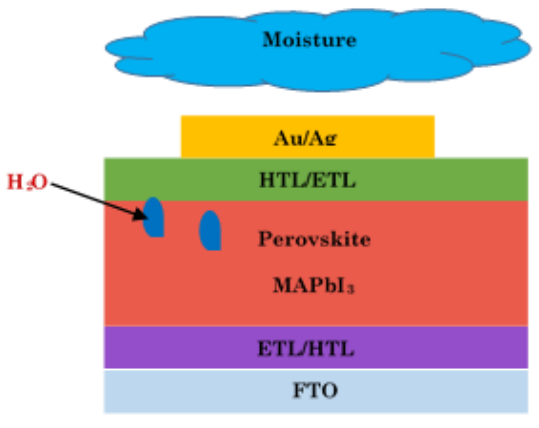

capability. However, limited by the low solubility and viscosity, it's difficult to form uniform and defect free PCBM films on the rough surface of perovskite. Moreover, the aggregation of PCBM results in the incomplete coverage on the perovskite layer, which induces charge recombination and accumulation at perovskite/PCBM interface, as well as the degradation of perovskite. An ultra-thin layer of poly(9-vinylcarbazol) (PVK) was introduced as interfacial layer between perovskite and PCBM to reduce carrier recombination and accumulation. PVK improve the contact property and the crystallization of perovskite layer, which greatly reduce trap density and carrier recombination. This interface modification leads to better thermal and moisture stability [13].

To improve stability of the cells, inorganic materials are used as interface layers. There are many transparent oxides used as alternative to $\mathrm{TiO}_{2}$ such as $\mathrm{SnO}_{2}, \mathrm{ZnO}, \mathrm{WOx}$ or $\mathrm{WO}_{3}$, and $\mathrm{Al}_{2} \mathrm{O}_{3}$, these materials need annealing temperature slightly above $130^{\circ} \mathrm{C}$.

The improvement in ambient stability of MAPbI3 based perovskite solar cell through barium (Ba) metal ion doping is reported [15]. Ba perovskite films shows higher crystallite size which leaded to the formation of larger grains. Ba doping is a simple and cheap way to enhance the long-term ambient stability of PSC without any encapsulation.

For achieving long lifetime, a high level of encapsulation is required. Stability of perovskite solar cells was improved by employing Norland Optical Adhesive/ polyethylene Terephthalate (NAO/PET) as moisture barrier layer is reported [14]. The PSCs encapsulated by NOA/PET show stability under approximately $540 \mathrm{~h}$ exposure to moisture. However, the nonencapsulated solar cells are immediately deteriorated in PCE.

Figure 2. $\mathrm{MAPbI}_{3}$ perovskite decomposition in the contact with moisture environment.

\section{CONCLUSION}

The performance of perovskite solar cells depends on the photoactive layer, the hole transport layer, the electron transport layer and the electrodes. Various architectures and structures are studied. Improving the performance of photovoltaic devices requires the development of new materials, optimization of cell structure and associated manufacturing technology. Results show that the use of an inorganic materials as HTL and ETL improves the stability of the cells. doping the HTL improves the electrical properties of the layer then enhance the efficiency also the use of a protective layer between hole transport layer and the anode enhance the yield. The use of carbon contacts improves the stability of the cells. To protect cells against moisture and oxygen and avoid degradation, encapsulation of the device using plastic materials is required. NAO/PET is good material as moisture barrier in perovskite cells. The toxicity of the lead used in the absorber layer is another disadvantage of this devices. To improve environmental impact lead-free perovskite materials and indium free electrodes are required. Tandem structures are used to enhance the yield. 


\section{REFERENCE}

1. S. Feng, D. Ding, A. Runa, T. Liu, P. Su, W. Yang, H. Yang, Vacuum. 166, 255-263 (2019).

2. C. Tian, A. Mei, S. Zhang, H. Tian, S. Liu, F. Qin, S. Xie. Nano Energy. 53, 160-167 (2018).

3. P.P. Boix, K. Nonomura, N. Mathews, S.G. Mhaisalkar, Mater. Today. 17, 16-23 (2014).

4. M.A. Mutalib, F. Aziz, A.F. Ismail, W.N.W. Salleh, N. Yusof, J. Jaafar, N.A. Ludin. Appl. Mater. Today. 13, 69-82 (2018).

5. G.E. Eperon, V.M. Burlakov, P. Docampo, A. Goriely, H.J. Snaith. Adv. Funct. Mater. 24, 151-157 (2014).

6. Y. Xiao, L. Yang, G. Han, Y. Li, M. Li, H. Li. Organic Electronics. 65, 201-206 (2019).

7. R. Singh, V.K. Shukla. Sol. Energy. 178, 90-97 (2019).

8. X. Li, J. Zhang, X. Zhu, J. Yu, K. Fan, K. Appl. Surf. Sci. 462, 598-605 (2018).

9. S. Wang, Y. Zhu, W. Sun, X. Miao, Z. Ma, C. Yang, C. Wang. Sol.Energy. 176, 118-125 (2018).

10. D. Selvakumar, G. Murugadoss, A. Alsalme, A.M. Alkathiri, R. Jayavel. Sol. Energy. 163, 564-569 (2018).

11. J.M. Kim, C.W. Jang, J.H. Kim, S. Kim, S.H. Choi. Appl. Surf. Sci. (2018)

12. H. Tanaka, Y. Ohishi, T. Oku. Synth. Met. 244, 128-133 (2018).

13. J. Zhang, W. Mao, J. Duan, S. Huang, Z. Zhang, W. OuYang, X. Chen. Electrochim. Acta. 318, 384-391 (2019).

14. B.J. Kim, J.H. Jang, J. Kim, K.S. Oh, E.Y. Choi, N. Park. Mater. Today. Commun. 100537 (2019).

15. J. Bahadur, A.H. Ghahremani, S. Gupta, T. Druffel, M.K. Sunkara, K. Pal. Sol. Energy. 190, 396-404 (2019).

\section{Creative Commons Attribution License 4.0 (Attribution 4.0 International, CC BY 4.0)}

This article is published under the terms of the Creative Commons Attribution License 4.0

https://creativecommons.org/licenses/by/4.0/deed.en_US 